\title{
Determining the Obstacles of Type 2 Diabetes Patients
}

\author{
Burak Arslan ${ }^{1}$, Özlem Duman², Afitap Özdelikara ${ }^{3}$ \\ ${ }^{1}$ Research Assistant, Department of Medical Nursing, Faculty of Health Sciences, Ondokuz Mayıs University, Samsun, Turkey \\ ${ }^{2}$ Nurse, Palliative Care Unit, Sivas Sample Hospital, Sivas, Turkey \\ ${ }^{3}$ Assistant Professor, Department of Medical Nursing, Faculty of Health Sciences, Ondokuz Mayıs University, Samsun, Turkey
}

Received: 14 February 2020, Accepted: 5 April 2020, Published online: 30 April 2020

(C) Ordu University Institute of Health Sciences, Turkey, 2020

\begin{abstract}
Objective: This study was carried out to identify the obstacles faced by Type 2 diabetes patients.

Methods: The study was conducted in the descriptive type and included 112 patients hospitalized in the internal medicine clinics of the Ondokuz Mayis University Health Practices and Research Hospital. The descriptive form and the "Diabetes Obstacles Questionnaire in Type-2 Diabetes Patients" were used in the study. As the average score obtained in the subscales of the questionnaire rises, the level of obstacles related to that area felt by patients increases.

Results: Of the patients who participated in the study, $60.7 \%$ were women, $53.6 \%$ were housewives, $48.2 \%$ were primary school graduates, $27.7 \%$ lived in districts and $92 \%$ reported the presence of at least one chronic disease other than diabetes. It was identified that $54.5 \%$ of the patients had been diagnosed with diabetes for 11 years and longer, 50.9\% had received diabetes education, $72.3 \%$ had relatives with diabetes, $64.3 \%$ used oral antidiabetics and $72.3 \%$ received insulin treatment. Among the patients, $35.7 \%$ stated that the hardest aspect of diabetes was "following a diabetic diet". Among the subscales of the Diabetes Obstacles Questionnaire, the lowest average score was -0.34 in the obstacles in "receiving advice and support" subscale, and the highest average score was 0.34 in the "obstacles in coping with diabetes" subscale

Conclusion: The fact that 7 of the 8 subscales of the diabetes obstacles questionnaire had negative averages in the study indicates that the patients' perception of obstacles in these areas was low. The only subscale with a positive average was the "barriers in coping with diabetes" subscale and the patients' perception of obstacles related to this area was higher. Based on the findings, it is recommended to increase the accessibility of diabetes education and the rate of receiving diabetes education, and that educated patients be re-evaluated periodically by the diabetes education nurse.
\end{abstract}

Key words: Diabetes, Handicap, Nursing

Suggested Citation: Arslan B, Duman O, Ozdelikara A. Determining the Obstacles of Type 2 Diabetes Patients. Middle Black Sea Journal of Health Science, 2020; 6(1):37-44

\section{Address for correspondence/reprints:}

Burak Arslan

Telephone number: +90 (542) 5790527

ORCID-ID 0000-0002-4981-2806
E-mail: burakarslanhacettepe221@gmail.com

DOI: $10.19127 / \mathrm{mbsjohs.689132}$

Note: This study presented as a verbal presentation at the 2nd International Nutrition, Obesity and Community Health Congress, 26-27 December 2019, İstanbullTurkey. 


\section{Introduction}

Diabetes Mellitus (DM) is a chronic metabolic disease that results in impaired carbohydrate, fat and protein metabolism caused by the insufficiency, absence or deficiency of the hormone insulin. There are different types of DM (Olgun and Celik, 2017). Type 2 diabetes accounts for more than $90 \%$ of all diabetes types and is the most common type (Olgun et al., 2014).

The prevalence of Type 2 diabetes is increasing rapidly due to factors such as population growth, aging societies, obesity and the increase in sedentary lifestyle (Samancioglu, 2016). The prevalence of diabetes in people between the ages of 20-79 in the world has been reported as $9.3 \%$. It is estimated that this will increase up to $10.9 \%$ in the world by 2045 (Saeedi et al., 2019). According to the 2016 World Health Organization (WHO) data, diabetes ranks seventh among the causes of death worldwide (WHO, 2018 Date Accessed: 13.01.2020). In the International Diabetes Federation (IDF) Atlas of Diabetes 2017, the prevalence of diabetes in Turkey has been reported as $12.54 \%$ (IDF, 2017). Diabetes is an important public health problem in Turkey and the world.

Since diabetes is a long-term disease, it requires life-long care and management (Uren and Yilmaz Karabulutlu, 2018). The management of diabetes includes lifestyle changes and multi-component selfcare activities such as diet, exercise, foot care, medication/insulin use and self-monitoring of blood glucose (Akaltun and Ersin, 2016). As patients must develop a lifestyle based on behavioral choices and practices, they are in the center of diabetes care (Uren and Yilmaz Karabulutlu, 2018).

In patients with type-2 diabetes, living with the disease leads to various obstacles (handicaps) (Pilv et al., 2016). The barriers patients face in selfmonitoring are related to their mental and personal characteristics and hinder their management of the disease (Kahraman et al, 2016). It has been shown that patient attitudes significantly affect the diabetes care, that the metabolic control levels of individuals with negative attitudes is worse, and that their $\mathrm{HbAlc}$ and blood pressure levels are also negatively affected (Kara and Cinar, 2011). Identifying obstacles that prevent adherence to diabetes management recommendations enables the planning of personalized diabetes education and provides guidance for better diabetes management (Orhan and Karabacak, 2016; Cimo and Dewa, 2017). This research was carried out to identify the obstacles experienced by type- 2 diabetes patients.

\section{Methods}

This study was carried out in the internal medicine clinics of the Ondokuz May1s University Hospital between June 2018 - and August 2018. This study included voluntary individuals receiving inpatient treatment, 18 years and older, living with the diagnosis of type- 2 diabetes for at least 1 year, no neuropsychiatric disabilities.

The ethics committee approval and permission were obtained from the institution where the study would be conducted, and verbal consent was obtained from all participants. The descriptive form prepared by the researchers and The Diabetes Obstacles Questionnaire (DOQ) were administered to the participants.

The descriptive form was prepared according to the literature to obtain sociodemographic and disease related data in line with the objectives of the study. The form consists of 12 questions in total, 5 of which are related to sociodemographic data and 7 are related to data pertaining to the disease diabetes.

The validity and reliability of the Diabetes Obstacles Questionnaire was studied by Kahraman et al. (2016) and it is a five-point Likert scaled questionnaire. It contains 8 subscales: medication obstacles, obstacles in self-monitoring, knowledge and belief obstacles, obstacles in diagnosis, obstacles in relationships with healthcare professionals, obstacles in lifestyle changes, obstacles in coping with diabetes, and obstacles in receiving advice and support. There is no total score or reverse scored item in the questionnaire that consists of 68 questions. Each item in the scale is valued between -2 and +2 . Evaluation is performed based on the average scores of the questionnaire's subscales. Negative scores indicate that the patients do not experience difficulty in the relevant area, and positive scores indicate that they do. The average score determined for each subscale reflects the degree of difficulty the patient faces in regard to this obstacle. Accordingly, positive scores obtained from the relevant subscale indicate the increasing severity of the obstacles encountered, while negative scores indicate the severity of the positive situation (Kahraman et al., 2016).

The analysis of the data was carried out using the IBM Statistical Package for Social Sciences Version23. Percentage, average, Levene's test, ANOVA, Tukey HSD and the Mann Whitney-U test were used in the analysis of the data. Data that did not conform to normal distribution were presented as median (min-max) and the level of significance was taken as $\mathrm{p}<0.05$. Research results were limited to the relevant sample and could not be generalized. 


\section{Results}

It was identified that among the 112 patients who participated in the study, $60.7 \%$ were women, $53.6 \%$ were housewives, $48.2 \%$ were primary school graduates, $60.7 \%$ had an income between 1001 $2500 \mathrm{TL}$, all of them over 50 years old and $27.7 \%$ lived in districts. It was identified that $50.9 \%$ of the patients had received diabetes education, $54.5 \%$ had been diagnosed with type- 2 diabetes for 10 years and longer, $92 \%$ also had a chronic disease other than diabetes, $72.3 \%$ had a relative with diagnosed diabetes, $64.3 \%$ used oral antidiabetics and $72.3 \%$ used insulin. Among the patients, 35.7\% stated that the hardest aspect of diabetes was "following a diabetic diet". The descriptive characteristics of the patients participating in the study and data related to the disease have been presented in Table- 1 .

The average scores of the questionnaire's subscales have been presented in Table-2. It was identified that the lowest average score among the questionnaire subscales belonged to the "obstacles in receiving advice and support" subscale with a score of $-0.34 \pm 0.72$ and that the highest score belonged to the "obstacles in coping with diabetes" subscale with a score of $0.34 \pm 0.50$ (Table-2).

When the distribution of the questionnaire subscale average scores of the patient's descriptive characteristics and disease related data was examined, it was identified that a difference was present in relation to the gender variable in the knowledge and belief obstacles subscale, and that women scored higher in this subscale $(\mathrm{p} \leq 0.05)$.

It was identified that there were differences between in the knowledge and belief obstacles and obstacles in relationships with healthcare professionals subscales in relation to education levels and that illiterate patients scored higher and had a higher perception of obstacles $(\mathrm{p}<0.05)$. It was also identified that the same patient group had a high average in the self-monitoring obstacles, obstacles in diagnosis, and obstacles in lifestyle changes subscales ( $>>0.05$ ).

It was determined that there was a statistically significant difference between the income level and the obstacles in self-monitoring and knowledge and the belief obstacles subscales. It was identified that the scores of these subscales and perception of obstacles related to this area increased as the income level decreased $(\mathrm{p}<0.05)$.

It was identified that the differences in the knowledge and belief obstacles and obstacles in relationships with healthcare professionals' subscales in relation to the area of residency were statistically significant $(\mathrm{p}<0.05)$. It was identified that the average
Table 1. Descriptive Characteristics and Disease-Related Data

\begin{tabular}{|c|c|c|}
\hline Variable & Number (n) & Percent $(\%)$ \\
\hline \multicolumn{3}{|l|}{ Gender } \\
\hline Male & 44 & 39.3 \\
\hline Female & 68 & 60.7 \\
\hline \multicolumn{3}{|l|}{ Profession } \\
\hline Housewife & 60 & 53.6 \\
\hline Retired & 23 & 20.5 \\
\hline Civil Servant & 6 & 5.4 \\
\hline Self employed & 19 & 17.0 \\
\hline Unemployed & 4 & 3.6 \\
\hline \multicolumn{3}{|l|}{ Education } \\
\hline Illiterate & 34 & 30.4 \\
\hline Primary school & 54 & 48.2 \\
\hline Middle school & 9 & 8.0 \\
\hline High school & 6 & 5.4 \\
\hline University & 9 & 8.0 \\
\hline \multicolumn{3}{|l|}{ Income } \\
\hline $0-500 \mathrm{TL}$ & 21 & 18.8 \\
\hline $501-1000 \mathrm{TL}$ & 8 & 7.1 \\
\hline $1001-2500 \mathrm{TL}$ & 68 & 60.7 \\
\hline $2501-5000 \mathrm{TL}$ & 13 & 11.6 \\
\hline $5001 \mathrm{TL}$ and higher & 2 & 1.8 \\
\hline \multicolumn{3}{|l|}{ Area of residence } \\
\hline Village & 30 & 26.8 \\
\hline Small town & 2 & 1.8 \\
\hline District & 31 & 27.7 \\
\hline City & 19 & 17.0 \\
\hline Metropol & 30 & 26.8 \\
\hline \multicolumn{3}{|l|}{ Diabetes education } \\
\hline Yes & 57 & 50.9 \\
\hline No & 55 & 49.1 \\
\hline \multicolumn{3}{|l|}{ Years of Diabetes } \\
\hline 1 - 3 years & 13 & 11.6 \\
\hline $4-6$ years & 16 & 14.3 \\
\hline $7-9$ years & 22 & 19.6 \\
\hline 10 years and longer & 61 & 54.5 \\
\hline \multicolumn{3}{|l|}{$\begin{array}{l}\text { Presence of non-diabetes } \\
\text { disease }\end{array}$} \\
\hline Yes & 103 & 92.0 \\
\hline No & 9 & 8.0 \\
\hline \multicolumn{3}{|l|}{ 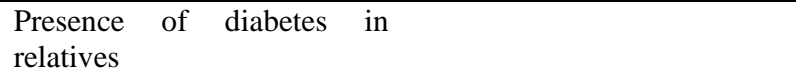 } \\
\hline Yes & 81 & 72.3 \\
\hline No & 31 & 27.7 \\
\hline \multicolumn{3}{|l|}{ Oral antidiabetic use } \\
\hline Yes & 72 & 64.3 \\
\hline No & 40 & 35.7 \\
\hline \multicolumn{3}{|l|}{ Insulin use } \\
\hline Yes & 81 & 72.3 \\
\hline No & 31 & 27.7 \\
\hline \multicolumn{3}{|l|}{ The most difficult aspect of } \\
\hline Life-long diet & 7 & 6.3 \\
\hline Doctor supervision & 1 & 0.9 \\
\hline Sexual problems & 25 & 22.3 \\
\hline Blood sugar imbalance & 29 & 25.9 \\
\hline Chronic complications & 10 & 8.9 \\
\hline Other & & \\
\hline
\end{tabular}


scores were higher than other groups for patients living in villages in the knowledge and belief obstacles subscale and for patients living in small towns in the obstacles in relationships with healthcare professional's subscale $(\mathrm{p}<0.05)$.
The mean value of the knowledge and belief obstacles scale score of patients who had not received diabetes education was found to be significantly high $(\mathrm{p}<0.05)$ (Table 3).

Table 2. Descriptive Data Related to the subscales of the Diabetes Obstacles Questionnaire

\begin{tabular}{|c|c|c|c|}
\hline $\begin{array}{l}\text { Subscales of the Diabetes Obstacles } \\
\text { Questionnaire }\end{array}$ & Mean \pm Standard Deviation & Min & Max \\
\hline Medication obstacles & $-0.28 \pm 0.55$ & -2.00 & 1.00 \\
\hline Self-monitoring obstacles & $-0.19 \pm 0.90$ & -2.00 & 2.00 \\
\hline Knowledge and belief obstacles & $-0.22 \pm 0.73$ & -2.00 & 1.88 \\
\hline Obstacles in diagnosis & $-0.11 \pm 0.73$ & -2.00 & 2.00 \\
\hline $\begin{array}{l}\text { Obstacles in relationships with } \\
\text { healthcare professionals }\end{array}$ & $-0.28 \pm 0.51$ & -1.88 & 1.29 \\
\hline Obstacles in lifestyle changes & $-0.09 \pm 0.57$ & -1.42 & 1.67 \\
\hline Obstacles in coping with diabetes & $0.34 \pm 0.50$ & -1.00 & 1.71 \\
\hline $\begin{array}{l}\text { Obstacles in receiving advice and } \\
\text { support }\end{array}$ & $-0.34 \pm 0.72$ & -2.00 & 1.57 \\
\hline
\end{tabular}

\section{Discussion}

In the study, it was identified that patients experienced the most obstacles in the "coping with diabetes" subscale (Table 2). Similar to this study, Kahraman et al. also reported that patients experienced the most obstacles in the coping with diabetes area (Kahraman et al., 2016). As with all chronic diseases, diabetes also makes it mandatory to maintain treatment follow-up and lifestyle changes besides the treatment process. It is reported that patients experience obstacles related to initiating and continuing treatment due to pre-conceived opinions of treatment, insulin injections, fear of pricking the finger and blood sugar monitoring (Celik and Pinar, 2014; Ong et al., 2014; Patel et al., 2015; Hassan et al., 2013). It has also been stated that functional insufficiency and feelings such as denial, shame, depression caused by the diagnosis of diabetes are also obstacles in the management of the disease (Akman and Olgun 2016; Baskurt et al., 2012).

In the study, it was determined that the gender variable affected the obstacles in the knowledge and belief area and that female patients experienced more obstacles related to this area $(p=0.05)$. There are studies in the literature reporting that women encounter more obstacles in the management of diabetes (Mansyur et al., 2015; Orhan and Karabacak, 2016; Uren and Karabulutlu, 2018; Egan et al., 2013). The result of the study is consistent with the literature.

In the study, it was determined that there were differences in the knowledge and belief obstacles and the obstacles in relationships with healthcare professionals subscales in relation to the education level, and that illiterate patients experienced more obstacles related to these areas $(\mathrm{p}<0.05)$. In the study of Tol et al. (2012), the education level of the patients was determined as one of the obstacles in coping with diabetes. In a study conducted by Akgun Sahin (2015), it was concluded that patients lacking information about the disease led them to display negative attitudes and that this result was related to their low education level. In the study by Akar et al. (2014), it was reported that the education level and the perception of obstacles related to diabetes was inversely correlated. In the literature, it has been reported that an insufficient education level poses an obstacle in various areas related to diabetes (Uchenna et al., 2010; Rhee et al., 2005). The result of the research is similar to the literature. Coping with diabetes requires cooperation with healthcare professionals and the effective use of more than one skill, in particular, literacy. Therefore, as the education level decreases, skills related to comprehending knowledge, questioning and making sense of it may become limited. It is thought that this is why the result was affected.

In the study, it was determined that the income level affects the self-monitoring and the knowledge and belief obstacles areas $(p<0.05)$. It was determined that as the income level decreased, patients experienced more obstacles in the self-monitoring and knowledge and belief areas. Results similar to the results of this study have been reported in the literature (Akar et al., 2014; Tol et al., 2012). It has been reported that low income levels in diabetes patients created obstacles in treatment and lifestyle 


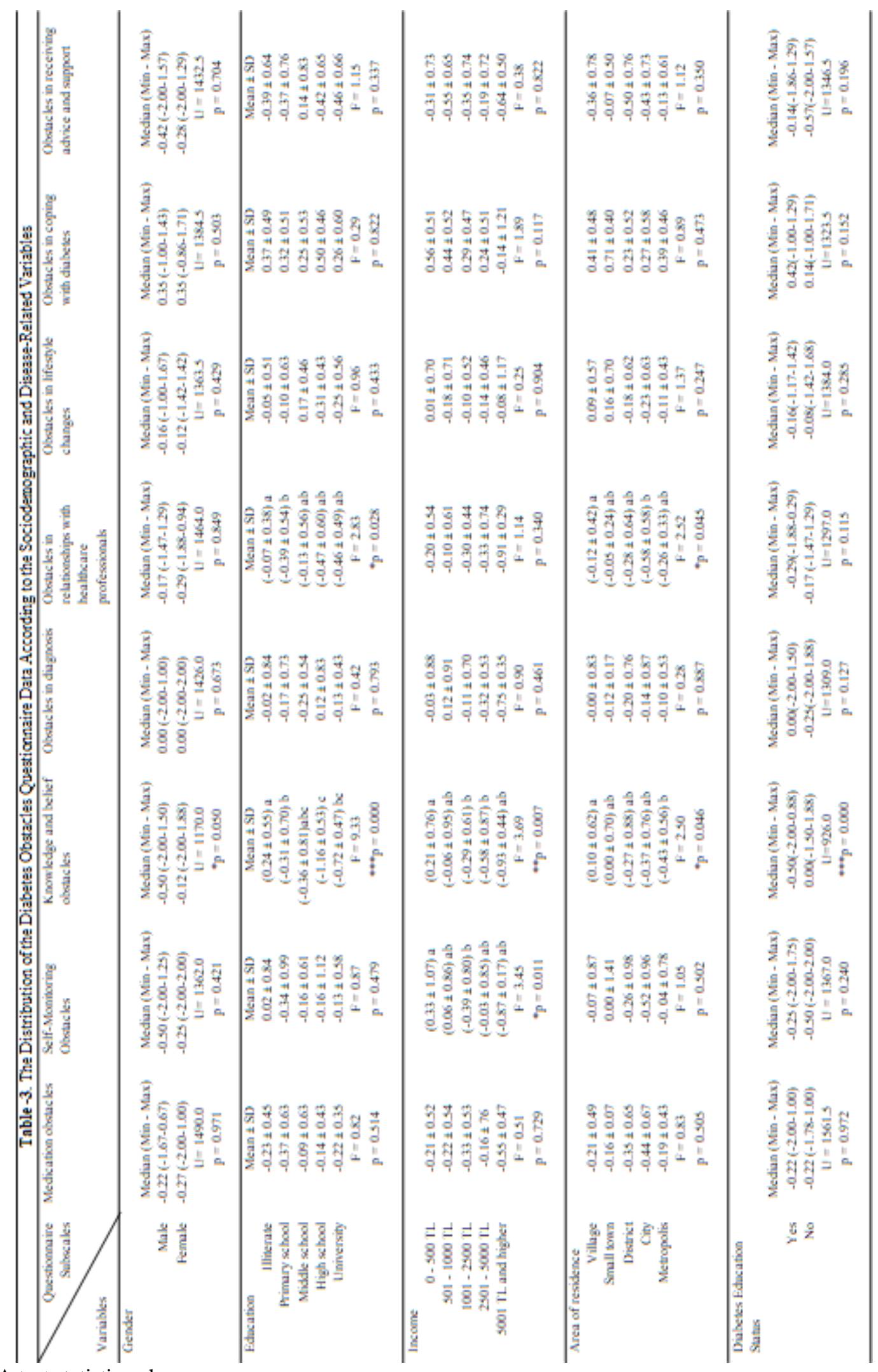

F: ANOVA test statistic value

U: Mann Whitney-U test statistic value

*a-b: The difference between different groups was statistically significant.

Tukey HSD was used for multiple comparison related with ANOVA.

$\mathrm{p}<0,05$ value was considered statistically significant. 
changes (Arda Surucu and Samancioglu, 2018; Marcy et al., 2011).It was identified in the study that there were differences in the knowledge and belief obstacles and obstacles in the relationships with healthcare professionals subscales in relation to the area of residency, and that the group that experienced the most barriers comprised patients who lived in villages and small towns $(\mathrm{p}<0.05)$. In Gedik's research, it was determined that diabetes patients who lived in villages had significantly low levels of selfefficacy in their management of diabetes, and that living in a rural area would increase obstacles in changing health behaviors (Gedik 2016; Schwarzer and Fuchs, 1995). It was stated that individuals living in rural areas experienced difficulty in access to healthcare services due to physical and social infrastructure insufficiency, that they could not benefit from home health services or municipal care services, and that this would pose an obstacle to disease management. In addition, the insufficiency of healthcare workers working in rural areas also prevents access to health care services (Avci and Gozum, 2018). This increases the obstacles of diabetes patients living in rural areas. It has also been reported that the low likelihood of rural individuals benefiting from applications such as telehealth and web-based education is also one of the obstacles that negatively affects the management of diabetes (Ross et al., 2015). The findings of the study are consistent with the literature. It was concluded that the disparity in healthcare accessibility and education levels between urban and rural residential areas in our country had affected the result.

In the study, it was identified that individuals who did not receive diabetes education experienced obstacles in the knowledge and belief area $(\mathrm{p}<0.05)$. In the study they conducted, Laranjo et al., 2015, reported that diabetes education was one of the fundamental interventions that reduced obstacles in the management of diabetes. There are research results indicating that receiving diabetes education is effective in facilitating diabetes related lifestyle changes (Austin 2006, Whittemore 2004).

\section{Conclusion}

Individuals living with the diagnosis of diabetes experience difficulties in making lifestyle changes in some areas of their lives. This creates a perception of obstacles in such individuals. In the study, it was identified that the patients' perception of obstacles was highest in the area of "coping with diabetes" and that the perception of obstacles in different areas was affected by gender, income levels, area of residence and receiving diabetes education.

In light of the findings, to increase the levels of receiving diabetes education among individuals diagnosed with diabetes, it is recommended to expand educational nursing services and to include strategies to cope with the disease and lifestyle changes beside technical skills in diabetes education programs for nurses. In addition, the delivery of diabetes nursing services to rural individuals will facilitate rural individuals in overcoming their obstacles.

Conflict of Interest Disclosure

Ethics Committee Approval: Ethics committee approval was received for this study from Ondokuz May1s University Clinical Research Ethics Committee

Peer-review: Externally peer-reviewed.

Author Contributions: Concept-A.O., Design-A. O.; Supervision A.O.; Materials- O.D.; Data Collection and/or Processing-B. A.; Analysis and/or Interpretation - B.A.; Literature Review-B.A., Writing-B.A., O.D., A.O.; Critical Review- A.O.

Conflict of Interest: No conflict of interest was declared by the authors.

Financial Disclosure: The authors declared that this study hasn't received no financial support.

\section{References}

Akaltun H, Ersin F. Determination of diabetes attitudes and behaviors of diabetic patients receiving home care services. DEUHFED 2016; 9(4), 126-133.

Akar Z, Bebis H, Ozdemir S. The Relationship between some sociodemographic features and health beliefs of diabetic patients. Journal of The Ege University Nursing Faculty 2014; 30(3): 3246.

Akgun Sahin Z. The attitude of patients with diabetes type 2 and the correlation between the problem fields ODU Journal of Medicine 2015; 2(3): 134138.

Akman H, Olgun N. Experience of adult individuals with Type 2 diabetes about diabetes: A qualitative study. International Diabetes Nursing 2016; 13(13): 29-36.

Alyaarubi S. Diabetes care in Oman: Obstacles and Solutions. Sultan Qaboos University Medical Journal 2011; 11(3): 343.

Arda Surucu H, Samancioglu S. Predictors of negative insulin treatment perception in individuals with type 2 diabetes. Turkey J Nurs Clinical Sci 2018; 10(2): 130-7. 
Austin MM. Diabetes Educators: partners in diabetes care and management. Endocrine Practice 2006; 12(1): 138-141.

Avci YD, Gozum S. Health service delivery models and tele-health for the elderly living in rural areas. TJFMPC 2018; 12(1): 56-67.

Celik S, Pinar R. Insulin Injection and Finger Sticking Fear in People with Diabetes. Journal of Psychiatric Nursing 2014; 5(2): 104-108.

Cimo A, Dewa CS. Symptoms of mental illness and their impact on managing type 2 diabetes in adults. Can J Diabetes 2018; 42(4): 72-381. doi: 10.1016/j.jcjd.2017.08.256.

Egan AM, Mahmood WAW, Fenton R, Redziniak N, Kyaw Tun T, Sreenan S, \& McDermott JH. Barriers to exercise in obese patients with type 2 Diabetes. QJM: An International Journal of Medicine 2013; 106(7): 635-638.

Gedik S. The level of diabetes management selfefficacy in patients with type 2 diabetes mellitus living in rural areas. Konya: Selcuk University Institute of Health Sciences. 2016.

Gunal A, Baskurt F, Baskurt Z, Parpucu Tİ, \& Yucekaya B. Relationship between perception of handicap and functional disability in elderly patients with type II diabetes. SDU Journal of Health Science Institute 2012; 3(1): 31-35.

Hassan A, Tohid H, Amin RM, Bidin MBL, Muthupalaniappen L, Omar K. Factors influencing insulin acceptance among type 2 diabetes mellitus patients in a primary care clinic: a qualitative exploration. BMC Family Practice 2013; 14: 164.

International Diabetes Federation (IDF) Diabetes Atlas 8th Edition. 2017. [cited 2020 Jan 13] Available from: URL: http://diabetesatlas.org/resources/2017-atlas.html.

Kahraman G, Gungor Tavsanli N, Baydur H, Ozmen $\mathrm{D}$, Ozmen E. The validity and reliability study of the diabetes obstacles questionnaire scale in type2 diabetes patients. Anadolu Psychiatry Journal 2016; 17(1): 33-4.

Kara K, Cinar S. The relation between diabetes care profile and metabolic control variables. Caucasian J Med Sci 2011; 1(2): 57-63.

Laranjo L, Neves AL, Costa A, Ribeiro RT, Couto L, Sá AB. Facilitators, barriers and expectations in the self-management of type 2 diabetes-a qualitative study from Portugal. European Journal of General Practice 2015; 21(2): 103-110.
Mansyur CL, Rustveld LO, Nash SG, Jibaja-Weiss ML. Social factors and barriers to self-care adherence in hispanic men and women with diabetes. Patient Education and Counseling 2015; 98(6): 805-810.

Marcy TR, Britton ML, Harrison D. Identification of barriers to appropriate dietary behavior in lowincome patients with type 2 diabetes mellitus. Diabetes Therapy 2011;2(1): 9-19.

Olgun N, Celik S. The Endocrine System and Related Disorders. Eti Aslan F, Olgun N, editors. Physiopathology. Ankara: Akademisyen Bookstore; 2017. p. 451-452.

Olgun N, Eti Aslan F, Cosansu G, Celik S. Diabetes Mellitus. Karadakovan A, Eti Aslan F, editors. Care in Internal and Surgical Diseases, Enhanced 3. rd Edition. Ankara: Akademisyen Bookstore; 2014. p. 779.

Ong WM, Chua SS, Ng CJ. Barriers and Facilitators to Self-Monitoring of Blood Glucose in People with Type 2 Diabetes Using Insulin: A Qualitative Study. Patient Prefer Adherence 2014; 8: 237-46.

Orhan B, Gulseven Karabacak B. Assciation Between Cognitive and Social Factors and Metabolic Control Parameters in Patients with Type 2 Diabetes. Clin Exp Health Sci 2016; 6(1): 1-8.

Patel N, Stone MA, McDonough C, Davies MJ, Khuntiand K, Eborall $\mathrm{H}$. Concerns and perceptions about necessity in relation to insulin therapy in an ethnically diverse uk population with type 2 diabetes: A qualitative study focusing mainly on people of south asian origin. Diabet. Med., 2015; 32: 635-644.

Pilv L, Vermeire E, Rätsep A, Moreau A, Nikolić D, Petek D, Yaman H, Oona M, Kalda R. Development and validation of the short version of the diabetes obstacles questionnaire (DOQ-30) in Six European Countries. Eur J Gen Pract 2016; 22(1): 16-22. doi: 10.3109/13814788.2015.1093619.

Rhee MK, Cook CB, El-Kebbi I, Lyles RH, Dunbar VG, Panayioto RM, \& George CD. barriers to diabetes education in urban patients' perceptions, patterns, and associated factors. The Diabetes Educator 2005; 31(3): 410-417.

Ross S, Benavides-Vaello S, Schumann L, Haberman M. Issues That Impact Type-2 Diabetes SelfManagement in Rural Communities. Journal of the American Association of Nurse Practitioners 2015; 27(11): 653-660. 
Saeedi P, Petersohn I, Salpea P, Malanda B, Karuranga S, Unwin N, ... \& Shaw JE. Global and regional diabetes prevalence estimates for 2019 and projections for 2030 and 2045: Results from The International Diabetes Federation Diabetes Atlas. Diabetes and Research Clinical Practice 2019; 157: 107843. Available from: https://doi.org/10.1016/j.diabres.2019.107843

Samancioglu S. Diseases of the Endocrine System and Nursing Management. Ovayolu N, Ovayolu O editors. The Fundaments of Internal Diseases Nursing and Chronic Diseases and their Different Aspects. Adana: Nobel Medical Bookstore 2016. p. 336.

Schwarzer R, Fuchs R. Changing Risk Behaviors and Adopting Health Behaviors: The Role of SelfEfficacy Beliefs. Self-Efficacy in Changing Societies 1995; 259: 288.

Tiktin M, Celik S, Berard L. Understanding adherence to medications in type 2 diabetes care and clinical trials to overcome barriers: A narrative review. Current Medical Research and Opinion 2016; 32(2): 277-287.

Tol A, Majlessi F, Rahimi FA, Shojaeezadeh D, Mohebbi B. Factors associated with supportive and coping obstacles of adjustment with type II diabetes. Journal of Health System Research 2012; 8(6): 1088-97.

Uchenna O, Ijeoma E, Pauline E, Sylvester O. Contributory factors to diabetes dietary regimen nonadherence in adults with diabetes. World Acad Sci Eng Technol 2010; 4(9): 644-51.

Uren Y, Yilmaz Karabulutlu E. Investigating the Factors that Complicate Diabetes Control in Patients with Type 2 Diabetes. HSP 2018;5(3): 376-386.

Whittemore R. Strategies to facilitate lifestyle change associated with diabetes mellitus. Journal of Nursing Scholarship 2004; 32(3): 225-232.

World Health Organization (WHO) The top 10 causes of death. 2018. [cited 2020 Jan 13] Available from: URL: https://www.who.int/newsroom/fact-sheets/detail/the-top-10-causes-ofdeath 